\title{
Air Pollution and Pregnancy
}

\section{Sheeba C*}

Associate Professor, Christian College of Nursing, Tamil Nadu, India

*Corresponding Author: Sheeba C, Associate Professor, Christian College of Nursing, Tamil Nadu, India.

\section{Introduction}

The developing fetus is more vulnerable to be affected by environmental pollutants. Researchers suggest that air pollution has adverse effects on maternal health and pregnancy outcomes including preterm birth, intrauterine growth retardation, low birth weight, and congenital anomalies.

\section{Common sources of air pollution}

Common sources of air pollution consist of vehicle exhaust, cigarette smoke (second-hand), construction activity, and burning of waste.

\section{Effect on fetus}

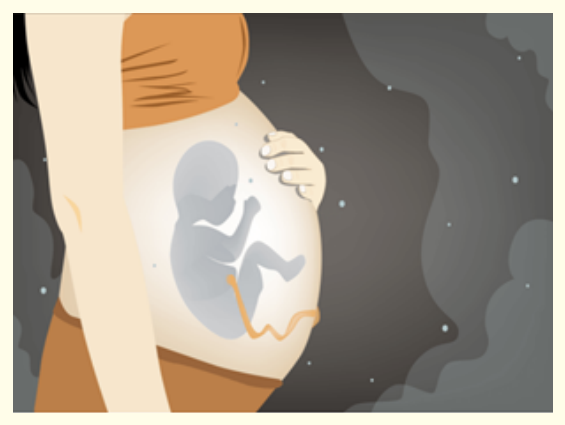

Figure
Received: March 11, 2020

Published: May 30, 2020

(C) All rights are reserved by Sheeba $\mathbf{C}$.
A combination of toxic solid and liquid particles floats in the air we breathe. Larger particles can be coughed or sneezed out of the body. But smaller particles get trapped in the lungs and enter into the bloodstream. The fetus receives oxygen from the mother. When the mother inhale polluted air, the fetus also affected by the pollutants present in the air.

Exposure to polycyclic aromatic hydrocarbons (PAHs), the most common pollutants of air, leads to premature birth and low birth weight. They are at great risk of developing autism and obesity in their childhood. Babies born with a low birth weight are at high risk of developing malnutrition. They are also at the risk of developing diabetes, cardiovascular diseases and hypertension (high blood pressure) in the long term course.

Dangers of air pollution during pregnancy:

- $\quad$ Low birth weight: Air Pollution causes babies to born with low birth weight. Even though the exact reason is unknown, this is likely to be due to reduced nutrient supply through the placenta.

- $\quad$ Preterm birth: Air pollution leads to premature birth, and thus causes neurological disorders and permanent physical disabilities in newborn babies.

- $\quad$ Autism: Study done by various researchers revealed that mothers exposed to air pollution during third trimester are at risk to deliver a child with autism. 
- Asthma: Asthma during pregnancy can lead to preeclampsia in mothers. If untreated, the baby suffers from lack of oxygen. This can cause poor growth, premature birth, and low birth weight.

- $\quad$ Risk of miscarriage: Studies found that prolonged exposure to air pollution causes miscarriages. Air pollution also causes infertility in men and women.

Ways to protect babies from air pollution:

- Listen to local radio, watch television and read newspapers for daily air pollution forecasts and stay at home when levels are alarming.

- Avoid travelling in car to limit exposure to vehicle exhaust.

- $\quad$ Stop smoking. Encourage smokers in your home to quit smoking.

- Using exhaust fan in the kitchen and see that the kitchen is well-ventilated because cooking is one of the highest sources of pollution in homes.

- Avoid fragrant and perfumed products like air fresheners, cologne, perfume and cleaners in the home which may contain toxic chemicals that get into the air.

- Make use of natural cleaners like vinegar, peroxide, and baking soda, or choose nontoxic brands.

- Install and maintain gas stoves, central heating and airconditioning systems properly.

- $\quad$ Check home for radon, a radioactive gas by a professional inspector.

- Install air purifier to filter harmful pollutants out of the air [1-8].

\section{Conclusion}

Children are the pillars of future nation. It is the responsibility of the parents and the government to provide them a harm free environment to develop and grow to serve the nation.

\section{Bibliography}

1. World Health Organization (WHO). "Ambient (outdoor) air quality and health".
2. March of Dimes. "Low Birthweight".

3. Environmental Health Perspectives (EHP). "Air Pollution and Birth Weight: New Clues about a Potential Critical Window of Exposure".

4. Science Daily. "Outdoor air pollution tied to millions of preterm births".

5. Environmental Health Perspectives (EHP). "Autism Spectrum Disorder and Particulate Matter Air Pollution before, during, and after Pregnancy: A Nested Case-Control Analysis within the Nurses' Health Study II Cohort".

6. March of Dimes. "Asthma during pregnancy".

7. Asthma UK. "Is pollution affecting your asthma? Find out how to manage this common asthma trigger".

8. American Society for Reproductive Medicine, US National Library of Medicine National Institutes of Health. "Outdoor air pollution and human infertility: a systematic review".

\section{Assets from publication with us}

- Prompt Acknowledgement after receiving the article

- Thorough Double blinded peer review

- Rapid Publication

- Issue of Publication Certificate

- High visibility of your Published work Website: www.actascientific.com/ Submit Article: www.actascientific.com/submission.php Email us: editor@actascientific.com

Contact us: +919182824667 